\title{
EXPERIMENTAL STUDY OF HEAT TRANSFER BETWEEN THIN LIQUID FILMS FLOWING DOWN A VERTICAL STRING IN THE RAYLEIGH-PLATEAU INSTABILITY REGIME AND A COUNTERFLOWING GAS STREAM
}

\author{
Zezhi Zeng, Abolfazl Sadeghpour, Gopinath Warrier, and Y. Sungtaek Ju*
}

\begin{abstract}
Direct contact heat exchangers based on wetted string columns offer an intriguing alternative to packed beds and spray columns. We experimentally examine the flow and heat transfer characteristics of thin liquid films flowing down strings of a diameter approximately 1 $\mathrm{mm}$ against a counterflowing air stream. Numerical simulations are also performed to help interpret and validate our experimental results. The Rayleigh-Plateau instability caused by interplay among surface tension, gravity, and viscous forces leads to the formation of uniformly spaced drop-like liquid beads traveling down a string. The liquid mass flow rate and also the nozzle radius influence the radius and spatial/temporal frequency of liquid beads. Aerodynamic drag exerted by the counterflowing air stream deforms liquid beads. The relationship between flow characteristics and heat transfer effectiveness are examined experimentally for different combinations of the air velocities, liquid mass flow rates, and nozzle radii. We show that the liquid mass flow rate and the air velocity are two primary factors influencing heat transfer effectiveness whereas details of the liquid flow instability affect local bead-to-air heat transfer coefficients. We also compare the heat transfer effectiveness and the pressure drop between a wetted string column that consists of an array of vertical strings and a well-established structured packing that consists of vertical plates. The wetted string column is shown to deliver comparable heat transfer performance but at a lower air pressure drop than the structured packing. The present work helps improve our understanding of the flow and heat transfer performance of string-based direct-contact heat exchangers and helps build a foundation for their systematic design and optimization.
\end{abstract}

Keywords:

Heat exchanger; Direct contact; Thin liquid film; Rayleigh-Plateau Instability;

\section{INTRODUCTION}

Economic light-weight heat exchangers are an important enabling technology for a wide variety of engineering applications. One example is dry cooling of thermoelectric power plants, whose significant consumption of fresh water presents major challenges in the context of the water-energy nexus. Conventional air cooled condensers (ACCs) have found limited adoption due in large part to their high capital cost and heavy weight of metal fins [1]. Alternative heat exchanger technologies that can circumvent these limitations are urgently needed to enable wider adoption of dry cooling of thermoelectric power plants.

One option is to apply an indirect cooling scheme where steam is cooled in a surface condenser using an intermediate non-evaporating heat transfer fluid, which is in turn cooled by the ambient air in separate direct-contact heat exchangers. Low vapor pressure liquids, such as silicone oil or ionic liquids [2], may be used as the intermediate heat transfer fluid.

Packed bed columns, which incorporate tortuous flow paths for enhanced heat and/or mass transfer, are wellestablished direct-contact heat/mass exchangers [3]-[5]. They have been commonly used in chemical processing and syntheses. Relatively high gas-phase pressure drops and liquid mal-distributions, however, remain major challenges [6], [7]. Spray columns enhance heat and/or mass transfer by dispersing liquid droplets into gas streams [8]. However, small droplet residence times limit heat transfer efficiency [9]. Scaling up the number of liquid nozzles while preventing interference among adjacent nozzles also present practical difficulties.

One promising alternative is a DIrect-contact Liquid-onString Heat Exchanger (DILSHE), schematically illustrated in 
Fig. 1. Each DILSHE unit consists of a dense array of aligned polymer strings with a diameter of the order of $1 \mathrm{~mm}$. A heated coolant (after exiting a surface condenser, for example) is fed into the top reservoir of the DILSHE unit. As thin films of the liquid coolant flow along the strings, they form traveling liquid beads due to flow instabilities. The coolant films/beads are cooled by counterflowing air. The straight flow paths for the air lead to lower air pressure drop and higher gas load limits when compared with packed beds. By inhibiting radial liquid transport, DILSHE also reduces liquid mal-distributions. Inexpensive polymer strings enable construction of economic and low-weight cooling modules that can be readily scaled.

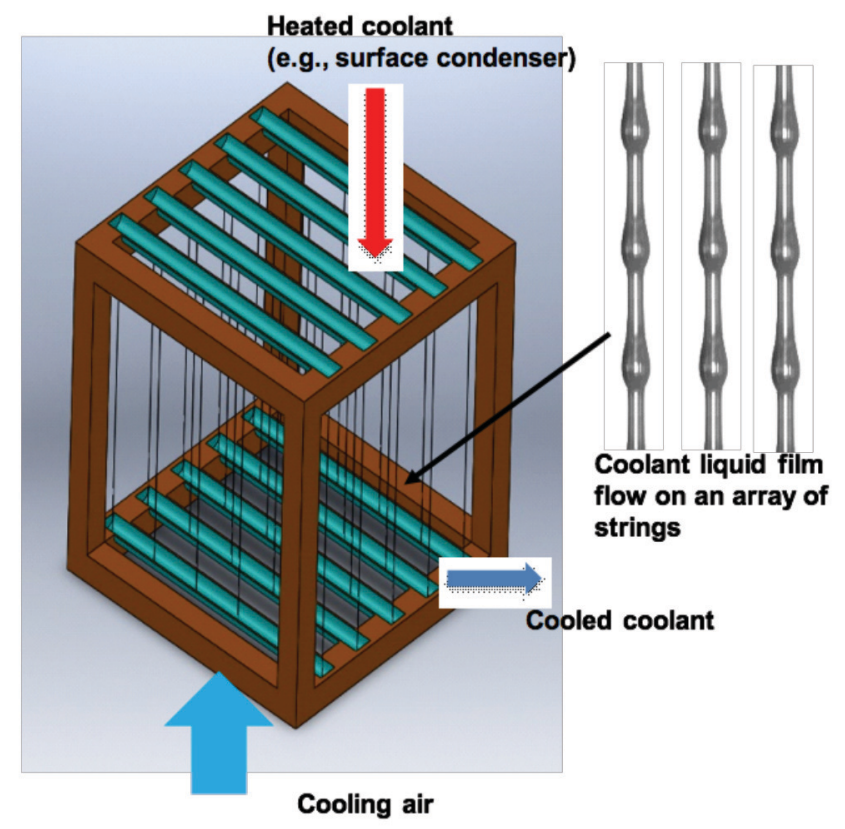

Fig. 1. Schematic of a DILSHE module. Such modules may be stacked in arrays to handle large cooling loads.

To enable physics-based systematic design of DILHSE, we need rigorous understanding of the fluid dynamics and heat transfer characteristics of liquid film flowing down a highly curved surface. Most studies of liquid films on solid surfaces were conducted using plates or tubes of diameters much larger than the film thickness [10]. Liquid films flowing over a highly curved surface [11] are unstable and form wavy profiles or traveling beads due to interplays among the surface tension, viscous and gravitational force. Two main types of instability experienced by such liquid films are the Rayleigh-Plateau (RP) instability [12], and the Kapitza instability [13]. Kliakhandler et al. [14] experimentally studied highly viscous liquids flowing along vertical strings and proposed a creeping-flow model to predict flow patterns in the inertia-less limit. Ruyer-Quil et al. [15] added the effects of inertia and viscous diffusion to the evolution equation for the local film thickness and the local flow rate and predicted spatiotemporal variations of the liquid film profiles. A later study [16] improved the model using a weighted-residuals approach and considered the effects of inertia, azimuthal curvature, and viscous dispersion. This then led to the classification of four different flow regimes. Duprat et al. [17] examined the response of liquid films flowing down a vertical string to inlet forcing and studied the transition from the absolute to the convective instability both experimentally and theoretically [18]. A later numerical modeling study based on a multi-fluid method [19] showed results consistent with the previous experimental data in select flow conditions [20].

Past studies also explored the use of liquid films flowing down strings for direct contact heat and mass transfer applications. Hattori et al. [21] presented approximate analytical models for the temperature distribution of a liquid film subjected to cross-flows of a cooling gas. A later study [22] performed $\mathrm{CO}_{2}$ absorption experiments where they compared the performance of spray columns, packed beds and wetted string columns and demonstrated the superiority of wetted string columns. Extending this work, Uchiyama et al. [7] reported an analytical model to predict the $\mathrm{CO}_{2}$ absorption performance. Migita et al. [23] constructed a prototype containing an array of 109 strings to study $\mathrm{CO}_{2}$ absorption effectiveness. They successfully demonstrated that, under the same inlet liquid and gas conditions, wetted string columns perform better in terms of absorption effectiveness and gas pressure drop over conventional packed columns and spray columns. Pakdehi et al. [24] investigated the hydrazine absorption by a wetted string column with different number of strings and confirmed the advantage of wetted string columns in gas-phase pressure drop. Hosseini et al. [25] developed a CFD model and performed a parametric study to examine $\mathrm{CO}_{2}$ absorption by a liquid film flowing along a single string. A recent study [26] also developed a numerical model for a $\mathrm{CO}_{2}$ absorption process in a wetted string column and reported good agreement with the previous experimental results [23].

More recent studies experimentally investigated the fluid dynamics of a single wetted string in the presence of significant counterflowing air [27] and compared $\mathrm{CO}_{2}$ absorption rates for liquid films flowing on single strings and planar surfaces [28]. They observed that both gas-side and liquid-side mass transfer coefficients of the wetted strings were higher than the planar liquid films due to film waviness associated with flow instability. Furthermore, due to efficient mixing enabled by recirculating liquid flows within liquid beads [9], [21], the mass (and also heat) transfer resistance across liquid films is small relative to the resistance across the liquid-air interface.

Many experimental studies focus on investigating heat transfer performance of a turbulent liquid film around a uniformly heated tube [29]-[37]. Shmerler et al. [30], [31] measured the wall heat flux and temperature gradients across the liquid films to develop correlations for the normalized liquid-side heat transfer coefficients and the Reynolds number. These experiments focused on subcooled liquid films or saturated liquid films undergoing evaporation. However, very few studies were reported on heat transfer characteristics of liquid films flowing down thin strings with a counterflowing gas. A previous study [9] reported a rather limited experimental investigation of the cooling of thin films of a heated silicone oil flowing down single strings. By using strings with different diameters, they successfully achieved the string-of-bead flow and annular film flow at the same liquid flow rate, and demonstrated that the string-of-bead flow exhibited a higher overall heat transfer coefficient than the annular film flow. However, the impact of the air velocity, liquid flow rate and nozzle radius on liquid film flow characteristics, and the relationship between the flow characteristics and heat transfer effectiveness still need further investigations. 
To rigorously understand the flow and heat transfer characteristics of thin liquid films flowing along strings, we previously experimentally studied the fluid dynamics of thin silicone oil film flowing down a vertical string against a counterflowing air stream. We demonstrated that the liquid flow rate and air velocity were two primary factors affecting the flow characteristics [38]. We then constructed a numerical model based on the geometric parameters obtained from our experiments to predict velocity distributions and temporal variations in temperature of liquid beads [39]. The simulation results of the average bead temperature evolution agree well with the prediction from an analytical model [21].

In the present article, we report a combined experimental and modeling study of the flow and heat transfer characteristics of thin liquid films flowing down a single string in the presence of a counterflowing cooling gas. We focus on the RayleighPlateau (RP) regime [17], where uniformly spaced drop-like liquid beads travel on a thin liquid substrate formed along the entire length of a vertical string. Using a high-speed camera and micro-thermocouples, we capture liquid film/bead profiles and temperatures at different air velocities and at different nozzle diameters. Finite element models are constructed to help interpret and validate experimentally obtained heat transfer characteristics.

In Section 2, we briefly discuss the flow regime map as it relates to our experimental focus. In Section 3, we discuss the experimental setup, procedures and simulation models. In Section 4, we present and discuss the results.

\section{DESCRIPTION OF FLOW REGIMES}

Previous studies [16], [17] suggested a flow regime map for thin liquid films flowing down a vertical string. The regime map (Fig. 2) is presented in the plane $R_{\mathrm{w}} / l_{\mathrm{c}}$ versus $\alpha=h_{\mathrm{N}} / R_{\mathrm{W}}$ to facilitate practical use. Here, $R_{w}$ is the string radius, and $l_{\mathrm{c}}$ is the capillary length of the liquid defined as (e.g., $1.5 \mathrm{~mm}$ for Rhodorsil v50 silicone oil). Here $\rho$ and $\gamma$ denote the liquid density and surface tension, respectively. The Nusselt thickness $h_{\mathrm{Nis}}$ the thickness of a cylindrical liquid film one would have for a given liquid flow rate in the absence of any instability. The aspect ratio $\alpha$, which is independent of the ratio $R_{w} / l_{\mathrm{c}}$, can be varied by changing the liquid flow rate. This approximate regime map does not account for the influence of the liquid substrate thickness and other complications [16].

The RP instability can be arrested by the mean flow when the film thickness $h_{\mathrm{N}}$ is sufficiently small compared with the ratio $R_{\mathrm{w}}{ }^{3} / l_{\mathrm{c}}{ }^{2}$. This arrest of the growth of the RP instability by the flow advection, often referred to as saturation [17], is characterized by the saturation number $\beta^{*}$ :

Here, the Nusselt average liquid velocity and the maximum velocity at the free interface are denoted as $u_{\mathrm{N}}$ and $u_{\mathrm{i}}$ respectively. The two are in turn functions of the aspect ratio $\alpha$ and the viscosity of the liquid. Note that, for a given liquid, $\beta^{*}$ is a function only of $\alpha$ and $R_{\mathrm{w}} / l_{\mathrm{c}}$.

The curve representing $\beta^{*}=1$ approximately divides the plane into two regions. On the left hand side of the curve, $\beta^{*}$ is larger than 1 and the characteristic time of growth of the RP instability is smaller than the characteristic time necessary to displace the waves over their length. One then expects the RP instability mechanism to dominate over the flow advection [18]. By analyzing the dispersion relation of traveling beads/ waves, one can determine $\beta^{*} 1.507$ as a more refined characteristic number defining transition between the absolute instability of the Rayleigh-Plateau instability regime and the convective instability.

We focus in the present study on the RP regime that exhibits the absolute instability where a uniform train of traveling liquid beads are observed along the entire length of a string. his greatly facilitates interpretation of our heat transfer characterization experiments. The black symbols in Fig. 2 represent the liquid flow rates studied in this article, ranging from $0.03 \mathrm{~g} / \mathrm{s}$ to $0.09 \mathrm{~g} / \mathrm{s}$.

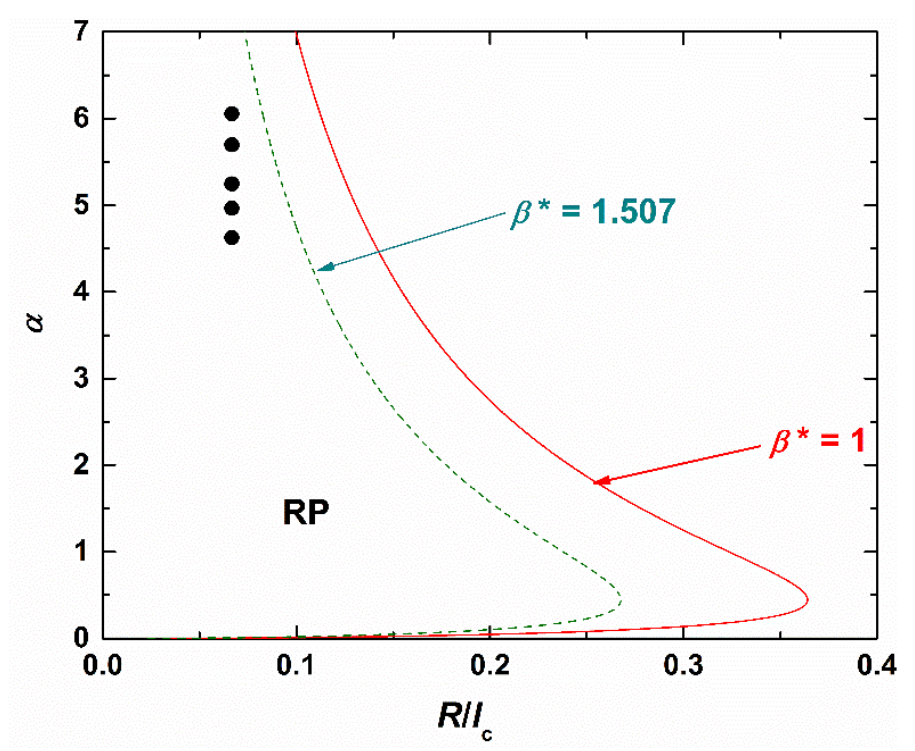

Fig. 2. A flow regime map proposed in an early study [17]. The regime map is constructed for v50 silicone oil. RP refers to the drop-like regime dominated by the Rayleigh-Plateau instability. Black symbols indicate the experiment conditions used in our study.

\section{EXPERIMENTAL SETUP AND NUMERICAL MODEL}

\subsection{Experimental}

Figure 3 shows a schematic of the experimental setup used in the present study. The setup consists of a vertical glass tube (inner diameter $=10.2 \mathrm{~mm}$ ), a top liquid reservoir, a polymer string and an air cone. The polymer string $\left(R_{w}=0.1 \mathrm{~mm}\right)$ with a weight attached at the end is suspended along the glass tube. The string is aligned using a X-Y stage to be concentric with a circular nozzle attached to the bottom of the liquid reservoir (Fig. 4). An electrical heater is used to heat the liquid inside the reservoir before it enters the nozzle.

After exiting the nozzle, the liquid flows along the string and is then collected at the bottom container. The collected liquid is fed back to the top reservoir using a gear pump.

Compressed air (inlet pressure $\sim 1.3$ bar, temperature $\sim 22$ ${ }^{\circ} \mathrm{C}$ ) is fed into the glass tube from the bottom. The converging cone at the bottom of the glass tube is fitted with a flow 
straightener to ensure uniform air distribution. A variable-area flow meter is used to measure the volumetric air flow rate.

A high speed video camera (capable of up to $16000 \mathrm{fps}$ ) is used to record liquid film profiles. These high-speed video recordings are analyzed using a custom made imaging processing code to extract the geometric parameters of the liquid films.

The liquid nozzle radius, $R_{\mathrm{n}}$ (Fig. 4) is one of the parameters that influence the liquid bead size and spacing. We use nozzles with three different radii, $0.4 \mathrm{~mm}, 0.5 \mathrm{~mm}$, and 0.6 $\mathrm{mm}$, in the present study. The uncertainty in nozzle radius measurement is $\pm 0.02 \mathrm{~mm}$.

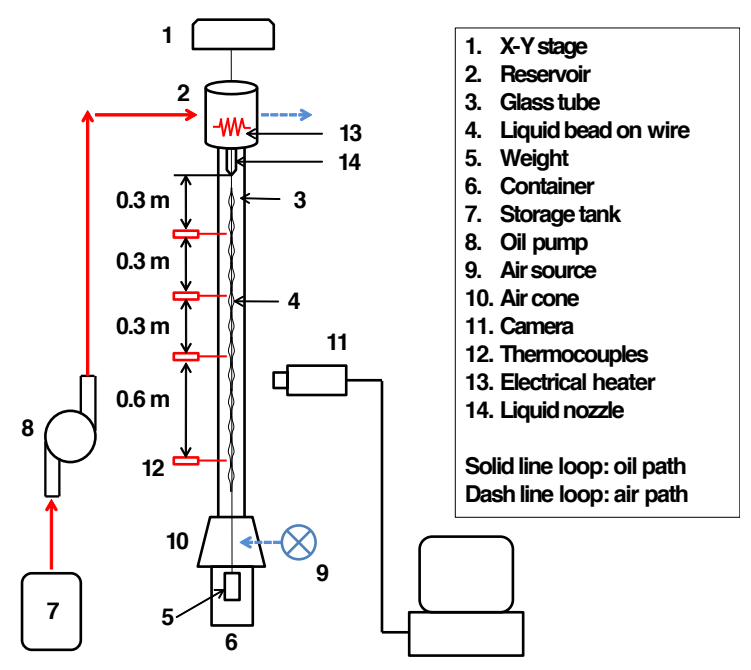

Fig. 3. Schematic of the experimental setup used to study flow and heat transfer characteristics of a non-evaporating liquid film flowing down a vertical string.

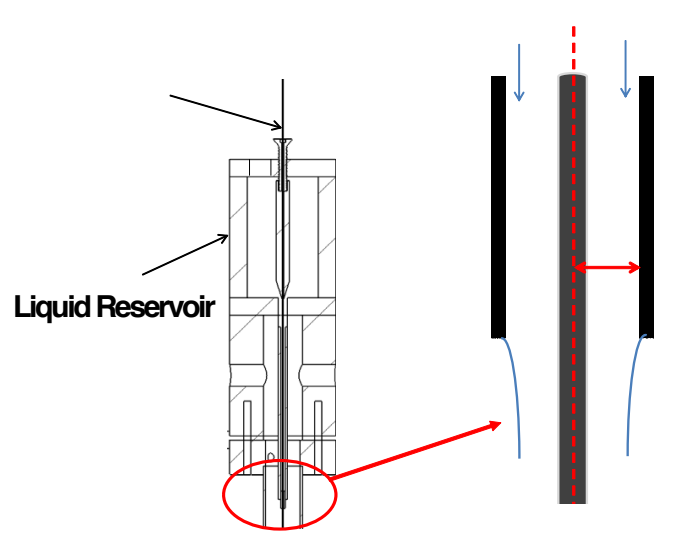

Fig. 4. An enlarged view of the top liquid reservoir and the liquid nozzle.

Four micro-thermocouples of diameter $250 \mu \mathrm{m}$ are placed at axial locations $0.3 \mathrm{~m}, 0.6 \mathrm{~m}, 0.9 \mathrm{~m}$, and $1.5 \mathrm{~m}$ from the nozzle to measure liquid temperatures. The thermocouples are mounted on the shafts of micro-positioners so that we can adjust their positions to coincide with the center of traveling liquid beads. Outputs from the thermocouples are monitored using a 24-bit high-precision data acquisition system. The power applied to the heater is adjusted for each flow rate such that the liquid temperature at the first thermocouple location is maintained at $37^{\circ} \mathrm{C}$.

A micro-thermocouple located at a fixed position is "immersed" to temporally varying extents in the liquid as a train of liquid beads travel past that location. Fast Fourier transform of the temporal temperature recordings therefore yields well-defined frequencies, which correlate well with liquid bead traveling frequencies obtained from video recordings as discussed further in Section 4.1.

We use a well-wetting liquid of low surface energy, Rhodorsil v50 silicone oil. Its key properties are: density $\rho=$ $963 \mathrm{~kg} / \mathrm{m}^{3}$, kinematic viscosity $v=50 \mathrm{~mm}^{2} / \mathrm{s}$, surface tension $\gamma$ $=20.8 \mathrm{mN} / \mathrm{m}$ at $20^{\circ} \mathrm{C}$, thermal conductivity $k=0.15 \mathrm{~W} /(\mathrm{m} \cdot \mathrm{K})$, and specific heat $c_{\mathrm{p}}=1507 \mathrm{~J} /(\mathrm{kg} \mathrm{K})$.

The liquid mass flow rate is calculated from the geometric parameters of the liquid beads and liquid substrates obtained through image analyses. In an independent set of experiments, we confirmed that the liquid mass flow rates measured using a weight scale placed under the bottom collection container agreed with those obtained using image analyses to within $10 \%$. The average air velocity in the glass tube is calculated from the measured volumetric flow rates.

Following a previous study [21], we quantify the liquid profiles in terms of $R_{b}$, the longitudinal distance between the centerline and the maximum curvature point along the bead; $R_{S}$, the radius of the cylindrical liquid substrate between two neighboring beads; and $L$, the distance between two adjacent travelling beads. Figure 5 schematically illustrates these geometric parameters for a representative case.

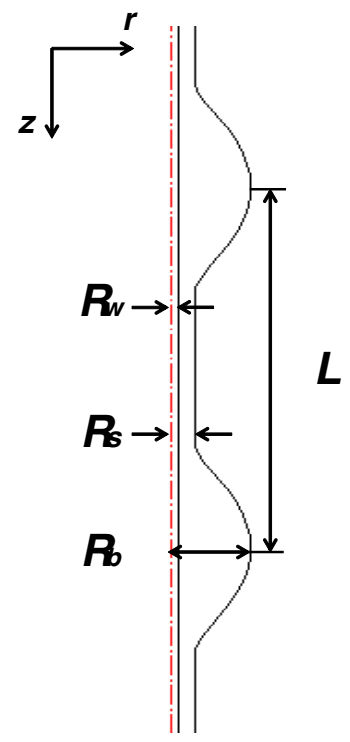

Fig. 5. Geometric parameters of liquid beads traveling along a string on a thin liquid substrate. 
The uncertainty in the geometric parameters obtained through optical image analyses is estimated to be $\pm 0.03 \mathrm{~mm}$. For each run, we typically analyze 3000 images for the bead radius, liquid substrate radius, and spacing between two subsequent beads. The uncertainty in the air velocity is estimated to be $0.1 \mathrm{~m} / \mathrm{s}$ and the uncertainty in thermocouple readings $\pm 0.1^{\circ} \mathrm{C}$.

\subsection{Numerical Model}

To help interpret and indirectly validate our experimental data, we construct a quasi-steady model for heat transfer between the liquid film and the counterflowing air. We note that the mean velocities of air are at least an order of magnitude higher than those of liquid beads in all our experiments. In view of this, our model assumes that liquid beads are stationary and considers only relative air flows. We further assume twodimensional axisymmetric flows.

Our experimental results are used to specify geometric parameters in the model: the thickness of the liquid film, the length and maximum radius of the liquid beads, and the spacing between beads. In our earlier work [40], we showed that the profile of liquid beads in the drop-like regime can be wellapproximated by that of a static liquid drop placed on a string coated with a cylindrical liquid substrate. We solve the Laplace equation to obtain the liquid bead profile using the experimentally determined liquid substrate thickness and maximum bead radius as input parameters.

A commercial computational fluid dynamics package was used for our simulation. The simulation domain and the relevant boundary conditions are summarized in Fig. 6. We solve the steady state Navier-Stokes equations and the energy equations, Eqs. (2-4), to obtain velocity fields and temperature distributions in both the liquid film and the air.

Here, $\boldsymbol{u}$ and $T$ are the velocity and temperature fields, respectively. $p$ is the pressure. $\boldsymbol{I}$ is the unit tensor. $\boldsymbol{F}$ denotes the gravitational force. $C_{p}$ is the heat capacity at constant pressure, $k$ the thermal conductivity, $\rho$ the density, and $\mu$ the dynamic viscosity.

The Navier-stokes equations are first solved to obtain the velocity fields. These were then input into the energy equation to obtain the temperature distributions. The velocity fields of the liquid and the air are coupled by the interface boundary conditions. At the liquid-gas interface, the zero shear stress condition, Eq. (5), the zero normal velocity condition, Eq. (6), and the tangential velocity continuity condition Eq. (7) are applied.
Here, $\boldsymbol{n}$ represents the normal vector. $\boldsymbol{u}_{\boldsymbol{l}}$ and $\boldsymbol{u}_{\boldsymbol{g}}$ denote the velocity fields in the liquid and the air, respectively.

The adiabatic condition $(-\mathbf{n} \cdot \mathbf{q}=0)$ and the no-slip boundary condition $\left(\boldsymbol{u}_{l}=0\right)$ are applied at the string surface. An isothermal wall condition is applied at the glass tube wall based on our experimental observation that there were negligible temperature variations along the glass tube wall. The ambient pressure is assigned at the outlets of the liquid and the gas. Heat conduction along the string and at the outlet is neglected.

A two-dimensional locally refined triangular mesh of approximately 240,000 elements was used for our simulation. The element size is varied gradually from $0.005 \mathrm{~mm}$ in the liquid substrate to $0.1 \mathrm{~mm}$ in the air. A mesh independence study was carried out to ensure that the liquid film temperatures do not change by more than $3 \%$ with further mesh refinement.

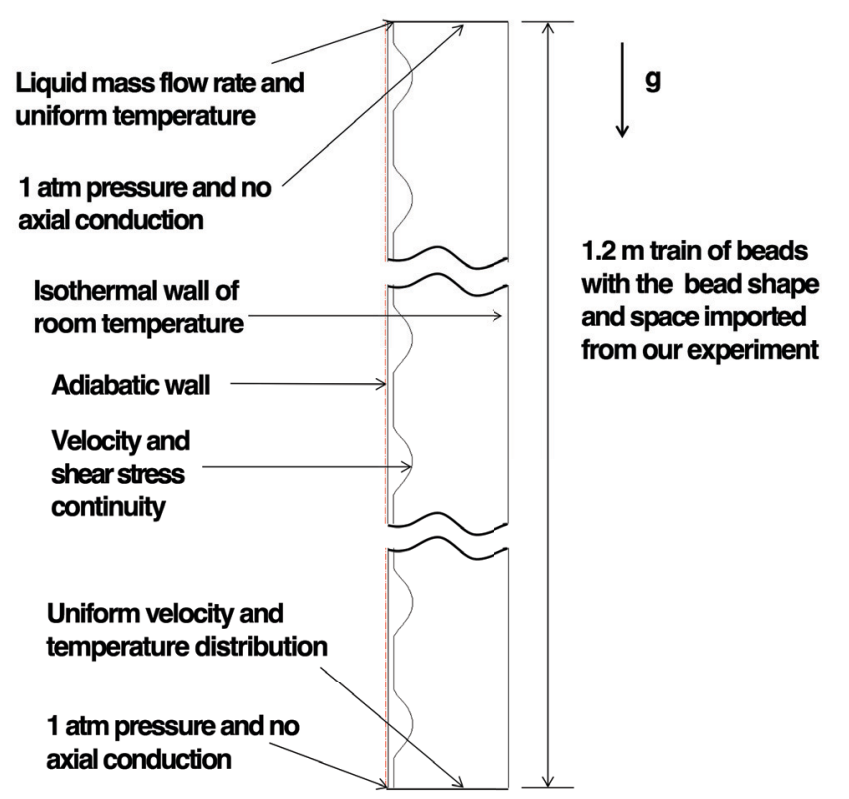

Fig. 6. The simulation domain and boundary conditions for our quasisteady model. All the geometric parameters of the liquid films are those obtained from the experiments.

\section{RESULTS AND DISCUSSION}

\subsection{Spatiotemporal diagrams}

To help quantify the flow characteristics of liquid films, we first construct a spatiotemporal diagram [41] from acquired video images. Briefly, at one chosen time step (i.e., video frame), we extract a vertical line of pixels, which is selected to pass through roughly the centers of liquid beads. We repeat this procedure for subsequent time steps at a constant time interval and then juxtapose the extracted pixel lines to reveal spatiotemporal trajectories of the beads.

Two representative spatiotemporal diagrams obtained from our experiment are shown in Fig. 7. Striations in the spatiotemporal diagram reflect the motions of constant height structures (i.e., traveling liquid beads). The spacing between adjacent striations in the $z$-direction corresponds to the spatial frequency of traveling beads. The spacing between adjacent 
striations in the $t$-direction corresponds to the temporal frequency. The slope of each striation represents the traveling velocity of each corresponding liquid bead.

In the RP instability regime, a series of parallel striations is observed along the entire length of a string, indicating that no coalescence of liquid beads takes place.
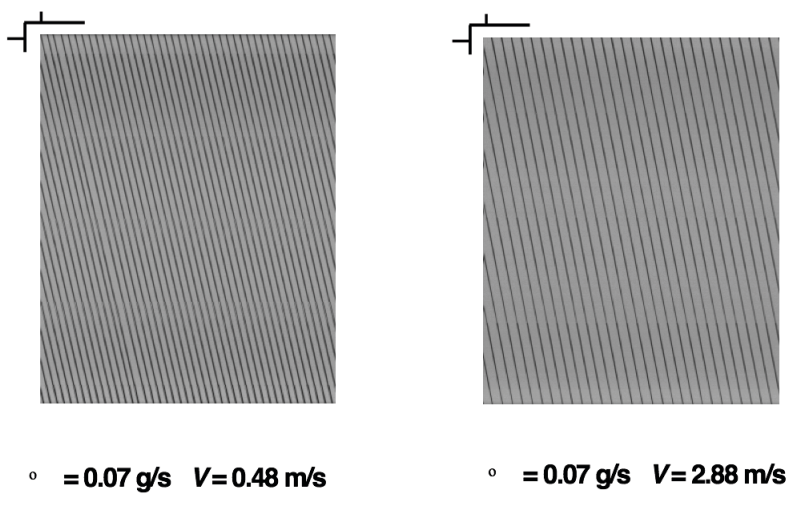

Fig. 7. Two spatiotemporal diagrams with the same liquid flow rate but different air velocities.

\subsection{Liquid bead radius and frequency}

A counterflowing air stream exerts aerodynamic drag on liquid beads and influences liquid film flow patterns. Comparing the two spatiotemporal diagrams shown in Fig. 7, for example, we note that the bead (spatial and temporal) frequencies are lower for the higher air velocity.

Figure 8 shows a set of optical images of liquid beads obtained at different air velocities for a fixed liquid mass flow rate. The bead radius $R_{b}$ increases slightly as the air velocity $V_{\text {air }}$ increases up to approximately $3 \mathrm{~m} / \mathrm{s}$. As the aerodynamic drag deforms the liquid beads, their frontal areas increase, further increasing the drag force. As the motion of the liquid beads becomes retarded, their volumes become larger, increasing the gravitational force to counteract the drag force. This increase in the liquid volume in turn leads to increase in the spacing between two adjacent beads and hence the bead frequency. That is, the liquid beads become bigger but fewer. The liquid bead radii and spatial frequency extracted from our image analysis are shown in Figs. 9-11.

As the air velocity is increased even further, the air streams turn turbulent. The liquid beads deform appreciably and may even be pushed upward by strong aerodynamic drag. We limit our heat transfer characterization to laminar air flows.

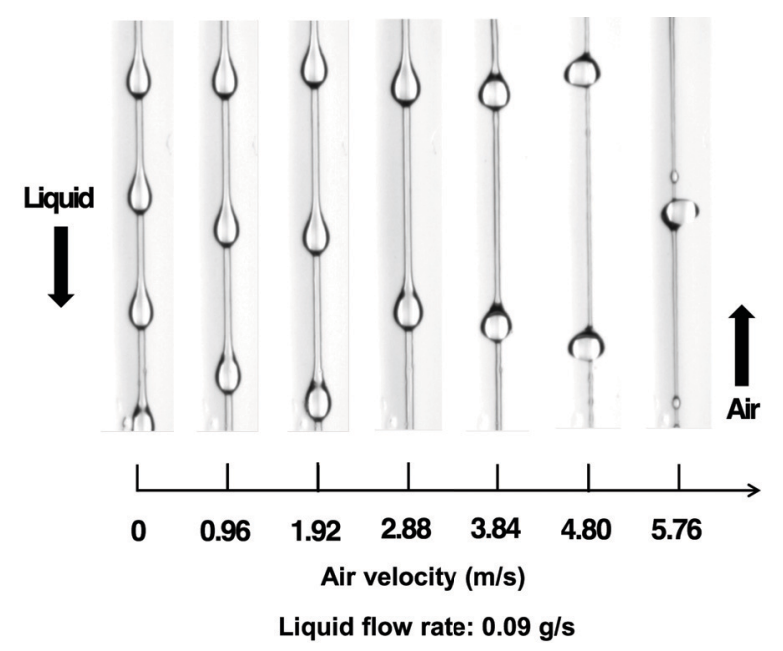

Fig. 8. Optical images of liquid film flows at different velocities of counterflowing air streams. The liquid flow rate is fixed at $0.09 \mathrm{~g} / \mathrm{s}$.

Figure 9 quantitatively shows variations in the liquid bead radius $R_{\mathrm{b}}$ as a function of the air velocity. The liquid mass flow rate $\dot{m}_{L}$ is varied from $0.05 \mathrm{~g} / \mathrm{s}$ to $0.09 \mathrm{~g} / \mathrm{s}$ by using nozzles with different values of the inner radius $R_{n}$.

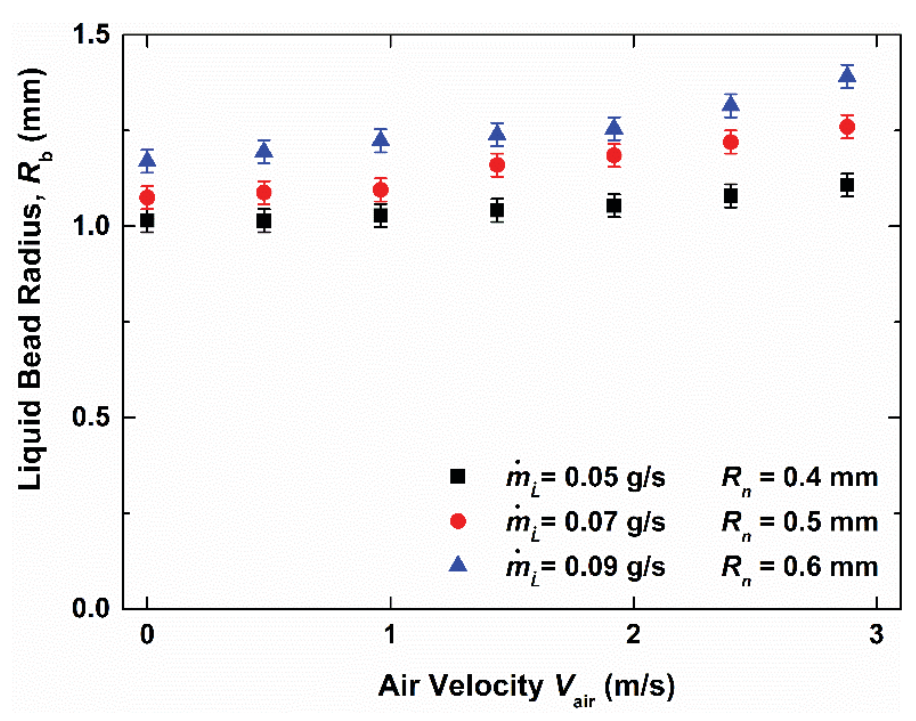

Fig. 9. Experimental results for the liquid bead radius, $R_{b}$, as a function of the air velocity, $V_{\text {air }}$. Three different liquid mass flow rates are achieved using nozzles of different radii.

One can also vary the liquid mass flow rate by adjusting the height of the liquid column in the top liquid reservoir while keeping $R_{n}$ constant. Figure 10 compares the measured values of $R_{b}$ from a set of experiments where we vary the mass flow rate in this manner for two nozzles of different radii $(0.4$ and $0.5 \mathrm{~mm}$ ). For a given nozzle radius, the measured bead radii at two different mass flow rates remain within $5 \%$ of each other. In contrast, at a fixed mass flow rate of $0.05 \mathrm{~g} / \mathrm{s}$, the measured bead radius for the nozzle with $R_{\mathrm{n}}=0.5 \mathrm{~mm}$ (triangles) is larger than that for the nozzle with $R_{\mathrm{n}}=0.4 \mathrm{~mm}$ (squares). The impact 
of these changes in liquid flow patterns on heat transfer will be discussed later.

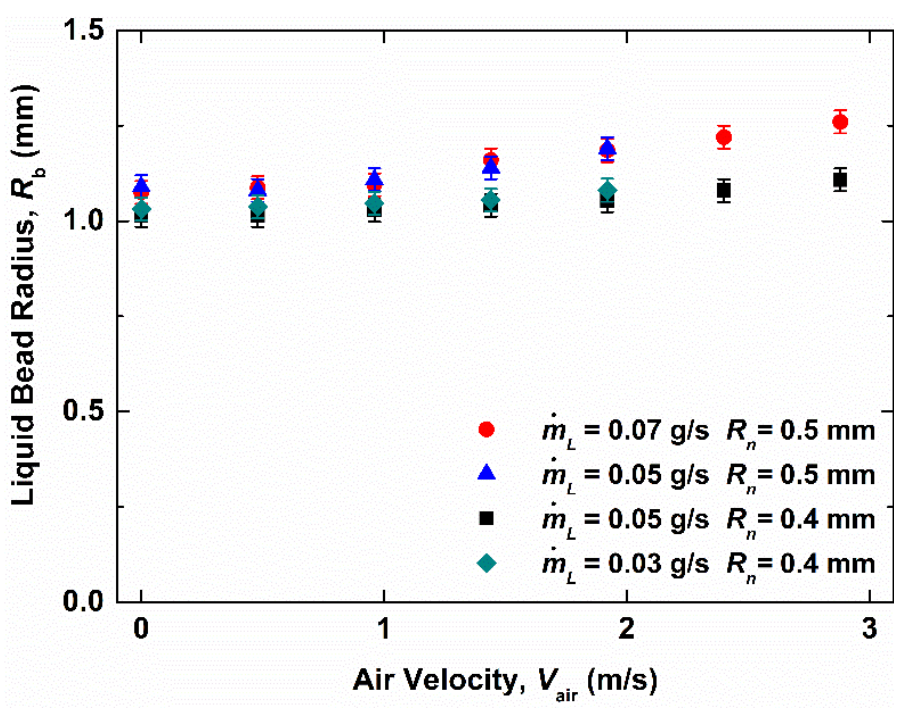

Fig. 10. Variations in the liquid bead radius $R_{b}$ for different combinations of the nozzle radii and liquid mass flow rates. A 0.4 mm-radius nozzle is used for liquid flow rates of $0.03 \mathrm{~g} / \mathrm{s}$ and $0.05 \mathrm{~g} / \mathrm{s}$. A $0.5 \mathrm{~mm}$-radius nozzle is used for liquid flow rates of $0.05 \mathrm{~g} / \mathrm{s}$ and $0.07 \mathrm{~g} / \mathrm{s}$. Both the $0.4 \mathrm{~mm}$ - and $0.5 \mathrm{~mm}$-radii nozzles are used to generate a liquid mass flow rate of $0.05 \mathrm{~g} / \mathrm{s}$.

Figure 11 quantitatively shows that the liquid bead frequency generally decreases with the increasing air velocity. More importantly, as the liquid bead size changes with the decreasing nozzle radius, from $0.5 \mathrm{~mm}$ (triangles) to $0.4 \mathrm{~mm}$ (circles), for a fixed mass flow rate of $0.05 \mathrm{~g} / \mathrm{s}$, the frequency of liquid beads changes in order to keep the mass flow rate constant. Figure 11 also shows that, for a given nozzle radius $\left(R_{\mathrm{n}}=0.4 \mathrm{~mm}\right)$, the smaller mass flow rate of $0.03 \mathrm{~g} / \mathrm{s}$ (squares) leads to the smaller bead frequency than the larger flow rate of $0.05 \mathrm{~g} / \mathrm{s}$ (circles).

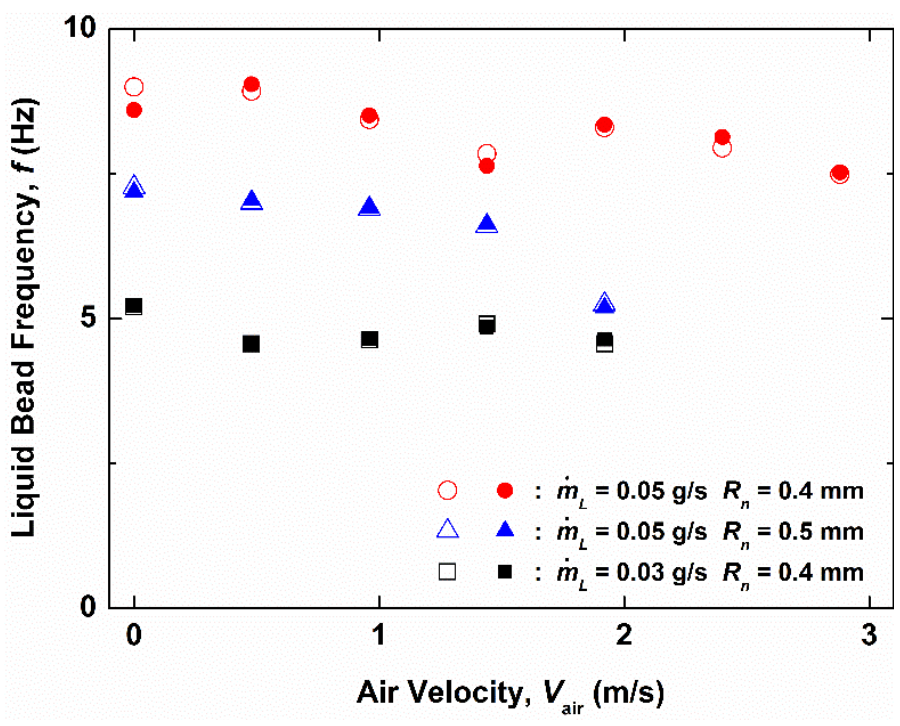

Fig. 11. The dependence of the bead frequency on the air velocity for liquid mass flow rates of $0.03 \mathrm{~g} / \mathrm{s}$ and $0.05 \mathrm{~g} / \mathrm{s}$. The frequencies are obtained either through optical image analyses or through FFT of temporal temperature recordings. The solid symbols correspond to the results from FFT, and the hollow symbols to the result from image analysis

Although the bead radius $R_{\mathrm{b}}$ increases with increasing $V_{\text {air }}$, the liquid substrate radius $R_{\mathrm{s}}$ (please see Fig. 5) remains nearly unaffected by the air flows. We estimate the liquid substrates account for less than $5 \%$ of the total liquid mass flow rate under the present experimental conditions.

A previous study [27] used liquids with different values of surface tension and made qualitatively similar observations. That is, for liquids with both high and low surface tension, the liquid bead radius increased with increasing gas loads whereas the liquid substrate thickness remained nearly unchanged. Large differences in the liquid flow rates and the resulting differences in the bead size and dominant instability mechanism, however, make direct quantitative comparison with the previous study difficult.

\subsection{Bead velocity}

Figure 12 shows the liquid bead velocity $V_{\mathrm{b}}$ as a function of $V_{\text {air }}$ for two nozzles with different radii. $V_{\mathrm{b}}$ is relatively insensitive to the air velocity for small liquid beads. $V_{\mathrm{b}}$ can be expressed as $V_{\mathrm{b}}=L \times f$, where $L$ is the spacing between two adjacent liquid beads and $f$ is the temporal bead frequency. Changes in the two parameters tend to offset each other as $V_{\text {air }}$ increases.

The bead velocities measured for $\dot{m}_{L}$ of $0.03 \mathrm{~g} / \mathrm{s}$ and 0.05 $\mathrm{g} / \mathrm{s}$ are nearly the same when the nozzle radius is fixed at 0.4 $\mathrm{mm}$. However, for a nozzle of $0.5 \mathrm{~mm}$ radius, $V_{\mathrm{b}}$ slightly increases with increasing $V_{\text {air }}$ for a given $\dot{m}_{L}$ and with increasing $\dot{m}_{L}$ for a given $V_{\text {air. }}$ This can be attributed to the fact that larger liquid beads are more susceptible to aerodynamic drag.

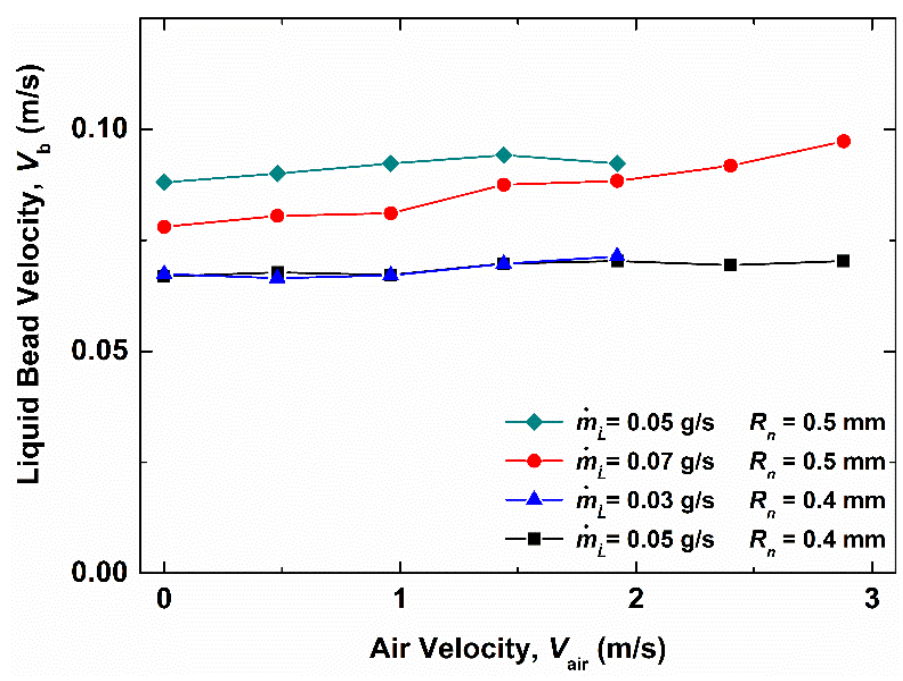

Fig. 12. The experimentally measured liquid bead velocity as a function of the air velocity. Four different liquid flow rates obtained 
using two different radii nozzle are shown. Note that the error bars are small compared with the plotted symbol.

\subsection{Overall heat transfer effectiveness}

Figure 13 shows the temperature drops measured at different axial locations as a function of $V_{\text {air. }}$. The liquid mass flow rate is set to be $0.05 \mathrm{~g} / \mathrm{s}$. The liquid temperature at $0.3 \mathrm{~m}$ from the nozzle exit (set to be $z=0$ ) is fixed at $37^{\circ} \mathrm{C}$ and this value is used as the reference temperature in calculating the temperature drops. The temperature drops increase with increasing $V_{\text {air }}$. This is due in part to enhanced forced convection and in part to increased spacing between liquid beads. The effect of spacing between adjacent liquid beads on heat transfer is further discussed later (Section 4.5). The experimental results agree well with our simulation results.

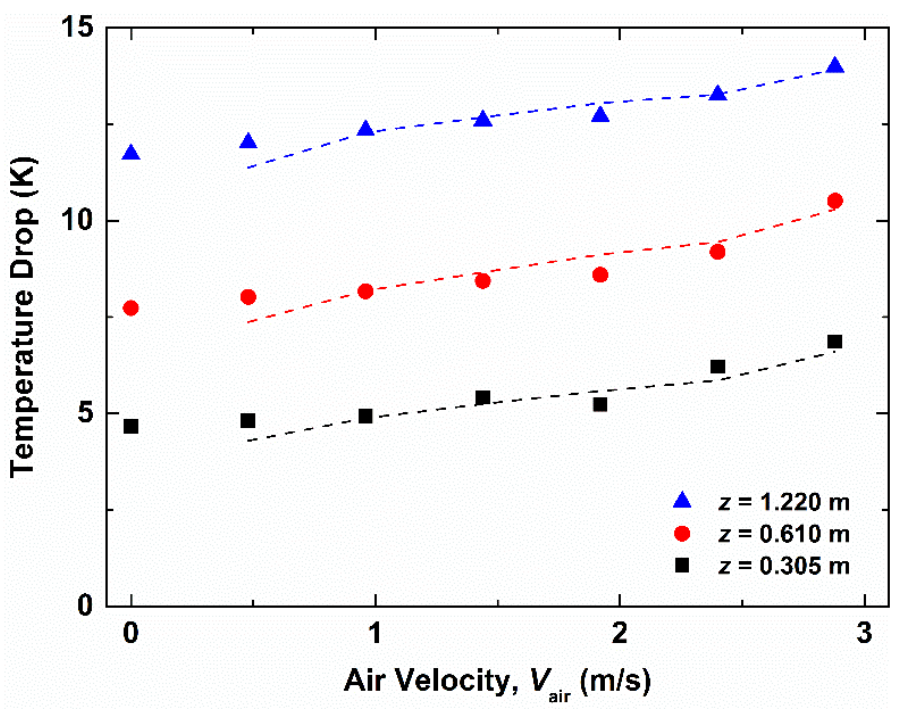

Fig. 13. Temperature drops measured as a function of the air velocity at three different axial locations. The liquid mass flow rate is $0.05 \mathrm{~g} / \mathrm{s}$. The solid symbols are experimental data. The dash lines are our simulation results. The uncertainties are smaller than the plotted symbols.

We use the "local" heat transfer effectiveness [42] at a specific downstream axial location to further quantify the heat transfer performance:

Here, $T_{\mathrm{L} 0}$ denotes the inlet liquid temperature, and $T_{\mathrm{G}}$ denotes the air temperature. We note that the mean air temperature remains nearly constant at $22{ }^{\circ} \mathrm{C}$ along the axial direction due to a relatively large glass tube diameter and hence air volume flow rates. The "local" heat transfer effectiveness is then only a function of the liquid heat capacity rate, $C_{\mathrm{L}}$, the minimum heat capacity rate, $C_{\min }$, and the liquid temperature at a specific axial location, $T_{\mathrm{L}}(z)$. In all the cases considered in our work, $C_{\min }=$ $C_{\mathrm{L}}$. The inlet liquid temperature and the inlet gas temperature are both fixed in all our experiments. We can therefore calculate the "local" heat transfer effectiveness using the liquid temperature profile alone.

Figure 14 shows the calculated heat transfer effectiveness as a function of the axial position $z$ for different liquid mass flow rates. The experimental results agree well with the predictions from our quasi-steady heat transfer model. For a given $V_{\text {air }}$, the local heat transfer effectiveness $\varepsilon_{\text {local }}$ improves as the liquid mass flow rate decreases, which is consistent with the general behavior of counterflow heat exchangers.

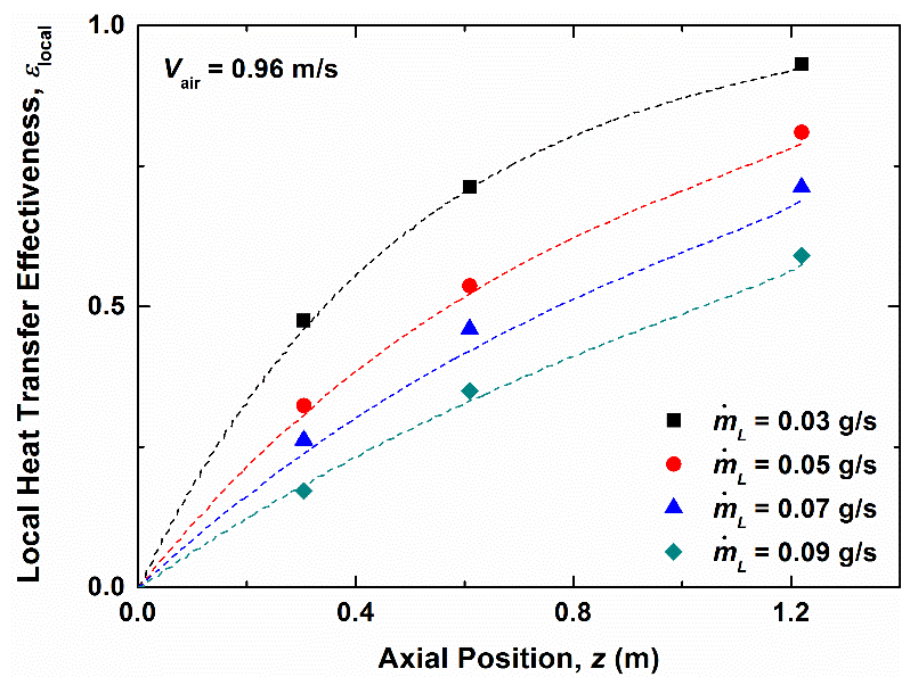

Fig. 14. The local heat transfer effectiveness as a function of the axial position. Four different liquid flow rates are examined. The symbols are experimental data and the dash lines represent our simulation results.

As noted before, a nozzle with a smaller radius generally produces smaller but more liquid beads than a nozzle with a larger radius at a fixed liquid mass flow rate. We examine the impact of this behavior on the heat transfer effectiveness. Our experimental results, shown in Fig. 15, indicate that the heat transfer effectiveness is rather insensitive to the liquid bead size $\left(R_{\mathrm{n}}=0.4 \mathrm{~mm}\right.$ versus $\left.R_{\mathrm{n}}=0.5 \mathrm{~mm}\right)$. Due to internal recirculation flows within liquid beads and hence efficient internal mixing [9], [17], [21], the details of liquid film profiles play a rather minor role. The total liquid mass flow rate is the dominant factor affecting the heat exchanger effectiveness. The same trends are observed for both air velocities $(0.96$ and $1.92 \mathrm{~m} / \mathrm{s})$ examined. 


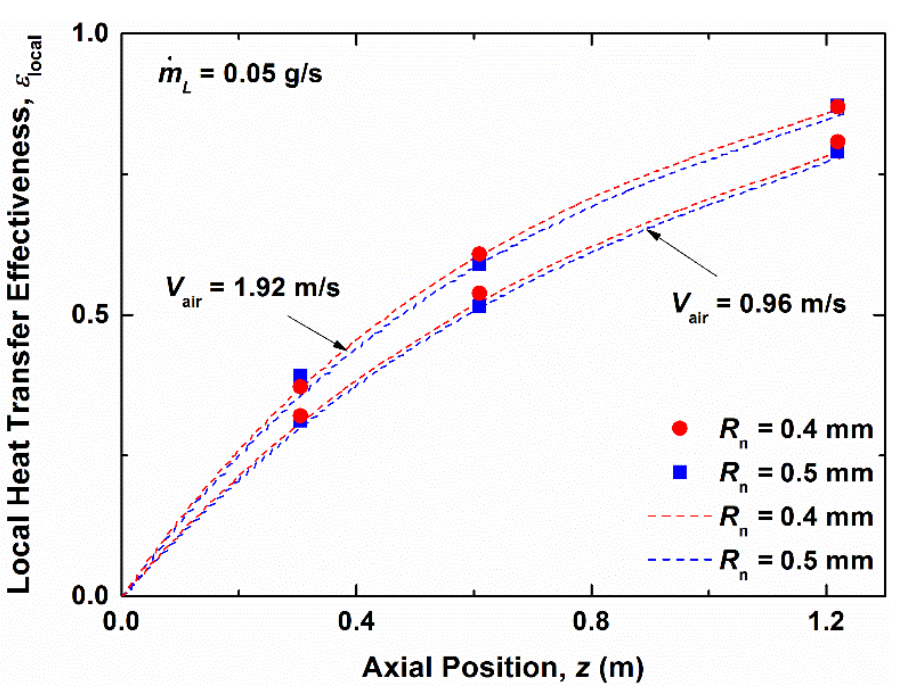

Fig. 15. Comparison of the local heat transfer effectiveness between the case with $R_{\mathrm{n}}=0.4 \mathrm{~mm}$ and the case with $R_{\mathrm{n}}=0.5 \mathrm{~mm}$ for the same liquid flow rate of $0.05 \mathrm{~g} / \mathrm{s}$. Two sets of results with different air velocities $(0.96 \mathrm{~m} / \mathrm{s}$ and $1.92 \mathrm{~m} / \mathrm{s})$ are shown. The symbols are experimental data and the dash lines are simulation results.

\subsection{Bead-to-air heat transfer coefficient}

Although the two cases with different nozzle radii discussed above deliver the same "local" heat transfer effectiveness $\varepsilon_{\text {local, }}$ "local" heat transfer coefficients for convective heat transfer between individual liquid beads and air $h$ can still differ.

To examine this further, we use a lumped capacitance analysis [43] to estimate the liquid bead-to-air heat transfer coefficient:

Here, $A_{\mathrm{s}}$ represents the surface area of a liquid bead and $V$ represents its volume. $\rho$ and $c$ represent the density and the specific heat of the liquid, respectively. $v$ represents the liquid bead velocity and $h$ represents the liquid bead-to-air heat transfer coefficient. Equation (9) is used to fit the measured axial temperature distribution and extract $h$.

Figure 15 shows the liquid bead-to-air heat transfer coefficients, $h$, obtained for the same two cases with different nozzle radii at a fixed $\dot{m}_{L}$ of $0.05 \mathrm{~g} / \mathrm{s}$. The heat transfer coefficient $h$ is larger for the bigger nozzle radius at a given $\dot{m}_{L}$ and a given $V$ air. A larger surface area of liquid beads exposed to the air and a larger inter-bead spacing lead to enhanced heat transfer for liquid film flows produced by the bigger nozzles.

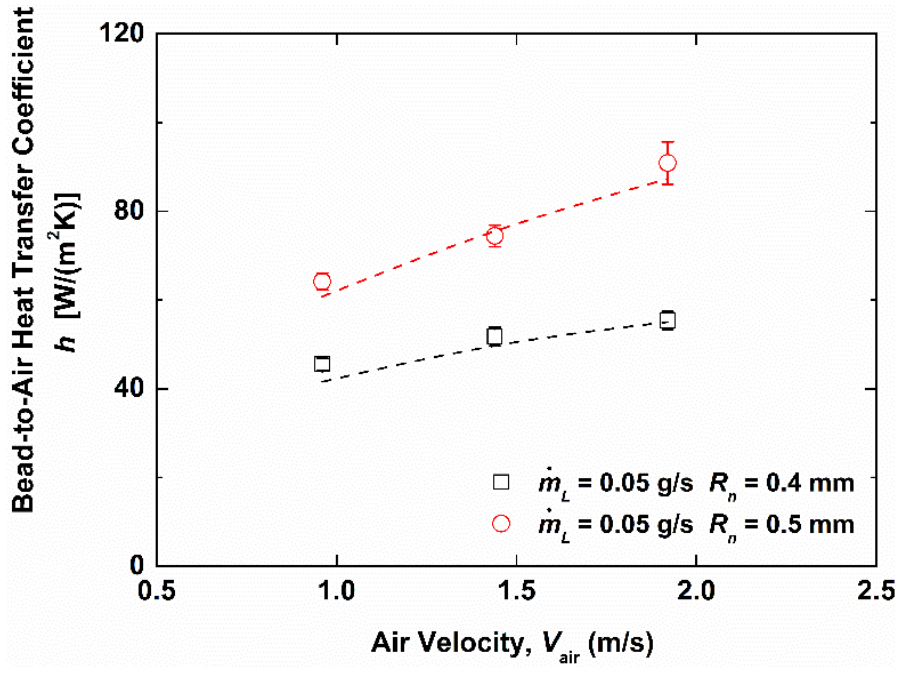

Fig. 16. The liquid bead-to-air heat transfer coefficient obtained from the lumped capacitance analyses. The results from the two nozzles with different radii $(0.4 \mathrm{~mm}$ and $0.5 \mathrm{~mm})$ are shown. The liquid flow rate, $\dot{m}_{L}$, is fixed at $0.05 \mathrm{~g} / \mathrm{s}$ are compared. The symbols are experimental data and the dash lines are simulation results.

When the inter-bead spacing is changed, the heat transfer rate is also changed due to the influence of recirculation/ wake zones formed in the inter-bead region [44]. Figure 17 compares representative streamlines and temperature profiles obtained in our numerical simulation for two cases with the same liquid bead size but different inter-bead spacing values (and hence different mass flow rates). At the larger inter-bead spacing, the flow separation angle (measured from the forward stagnation point) increases and the recirculation zone narrows in width. This then leads to increased radial temperature gradients and hence local heat transfer rates. A similar trend of enhanced heat transfer with increased inter-sphere spacing values was observed in an earlier study of linear arrays of spheres [45].

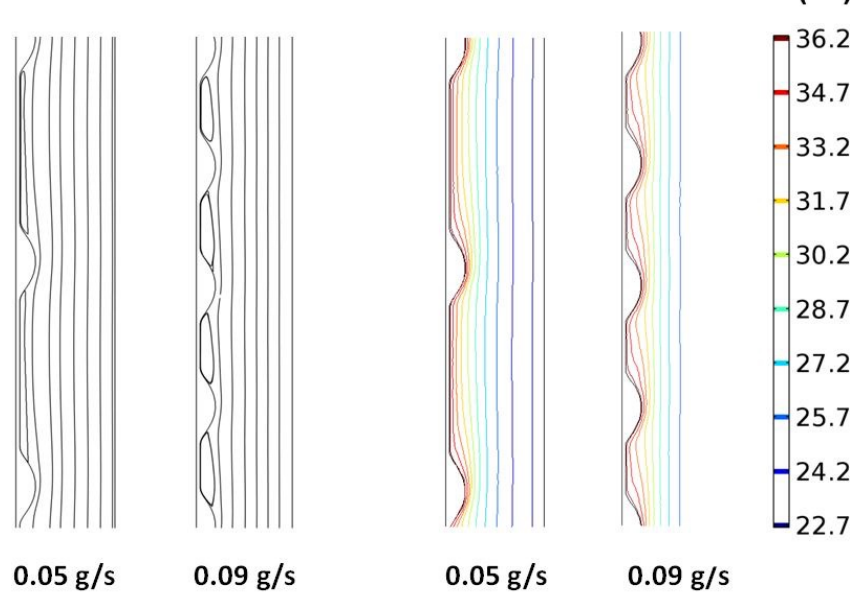

Fig. 17. The predicted streamlines (left) and temperature profiles (right) for liquid film flows with the same liquid bead size but with different inter-bead spacing values. 
Figure 18 compares the heat transfer coefficients obtained from two different mass flow rates for a fixed nozzle radius $R_{n}$. Under the conditions used, the liquid bead size and the bead traveling velocity remains nearly unchanged, whereas the interbead spacing is larger for the smaller liquid mass flow rate. And indeed, the lower mass flow rate leads to enhanced bead-to-air heat transfer coefficients.

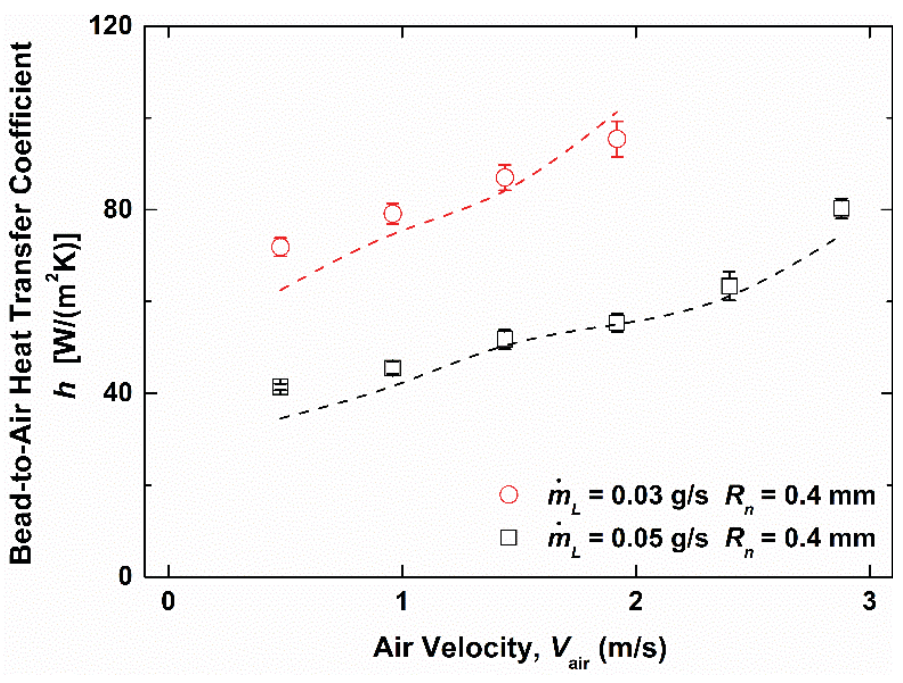

Fig. 18. The liquid bead-to-air heat transfer coefficients as a function of the air velocity. The nozzle radius is fixed while the liquid flow rate is changed from $0.03 \mathrm{~g} / \mathrm{s}$ to $0.05 \mathrm{~g} / \mathrm{s}$ by adjusting the liquid heads in the reservoir. The symbols are experimental data and the dash lines are simulation results.

Combining Eq. (8) and Eq. (9), we rewrite the "local" heat transfer effectiveness as

This offers one way to visualize how the heat transfer effectiveness for liquid films is nearly independent of the nozzle radii for a given value of $\dot{m}_{L}$. Changes in the heat transfer coefficient $h$ and the liquid bead velocity are counteracted by changes in the liquid volume and hence thermal capacitance of liquid beads.

\subsection{The comparison with a structured packing}

Liquid films falling down the surfaces of vertical plates or large-diameter tubes have been widely used for mass and heat transfer applications. Comparing heat transfer performance of these "planar" liquid films with that of liquid films flowing down on small-diameter strings is not straightforward as one must account for system-level constraints (for example, total cross-sectional area/volume).

For an illustrative purpose, we compare the heat exchange effectiveness and the gas-phase pressure drop in two different direct-contact heat exchangers. One consists of an array of wetted strings (our system) and the other incorporates a vertical plate structured packing [5], [46], [47] (Figure 19). The two systems have the same overall dimensions: $1 \mathrm{~m}$ wide, $1 \mathrm{~m}$ long and $1.2 \mathrm{~m}$ tall.
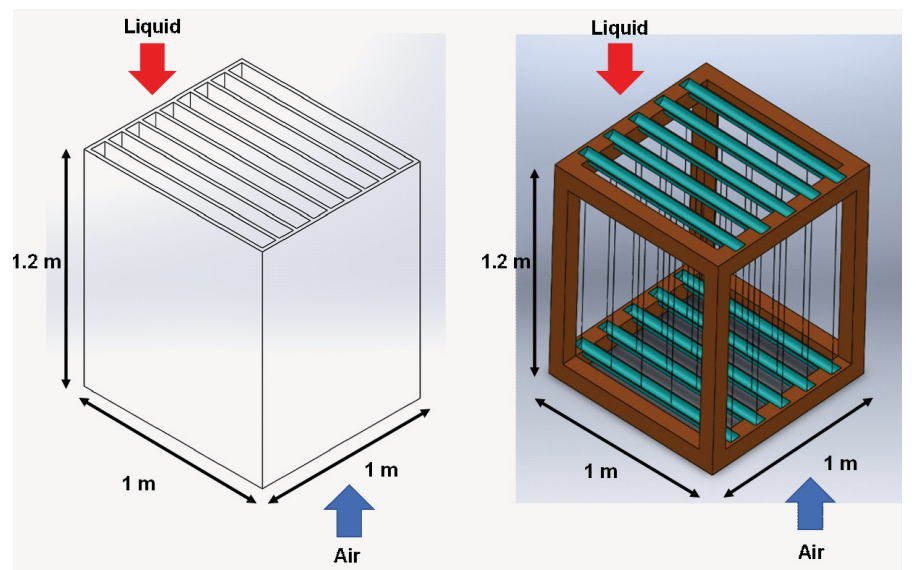

Fig. 19: The schematics of a wetted string column (left) and a vertical plate structured packing (right).

We keep the superficial liquid velocity $V_{L}=\dot{m}_{L} /\left(\rho_{L} A_{f}\right)$, and the superficial air velocity $V_{G}=\dot{m}_{G} /\left(\rho_{G} A_{f}\right)$ the same for both systems. Here, $\dot{m}_{L}$ and $\dot{m}_{G}$ denote the total inlet liquid and air mass flow rate, respectively. $\rho_{\mathrm{L}}$ and $\rho_{\mathrm{G}}$ denote the liquid and air density, respectively. $A_{f}$ is the column cross-sectional area (1 $\left.\mathrm{m}^{2}\right)$.

For our wetted string column system, the string pitch is selected to be $10 \mathrm{~mm}$, resulting in a total of 10,000 strings in the unit. For the vertical wall structure packing, we also choose the same $\mathrm{mm}$ pitch $(p=10 \mathrm{~mm})$. The plate thickness $t$ is set to be $1 \mathrm{~mm}$ such that the total thickness (plate and liquid films) is comparable to that for the wetted strings.

For the wetted string array, we use 3D numerical simulation over a square unit cell to predict the overall heat exchanger effectiveness $\varepsilon$ and pressure drop.

For a vertical plate structured packing, the heat exchanger effectiveness and the pressure drop are evaluated using the empirical correlations for the heat transfer coefficients and friction factor [5], [48]-[50].

Figure 20 shows the heat exchanger effectiveness of both the array of wetted strings and the structured packing as a function of the superficial air velocity. Two different superficial liquid velocities, consistent with our experimental values for a single string, are examined. Figure 20 shows that the array of wetted strings has generally higher heat exchanger effectiveness values than the structured packing. At the higher liquid superficial velocity, the heat exchanger effectiveness is lower for both systems. For the lower $V_{L}$, especially at sufficiently high air velocities, the two systems exhibit nearly identical heat transfer performance. 


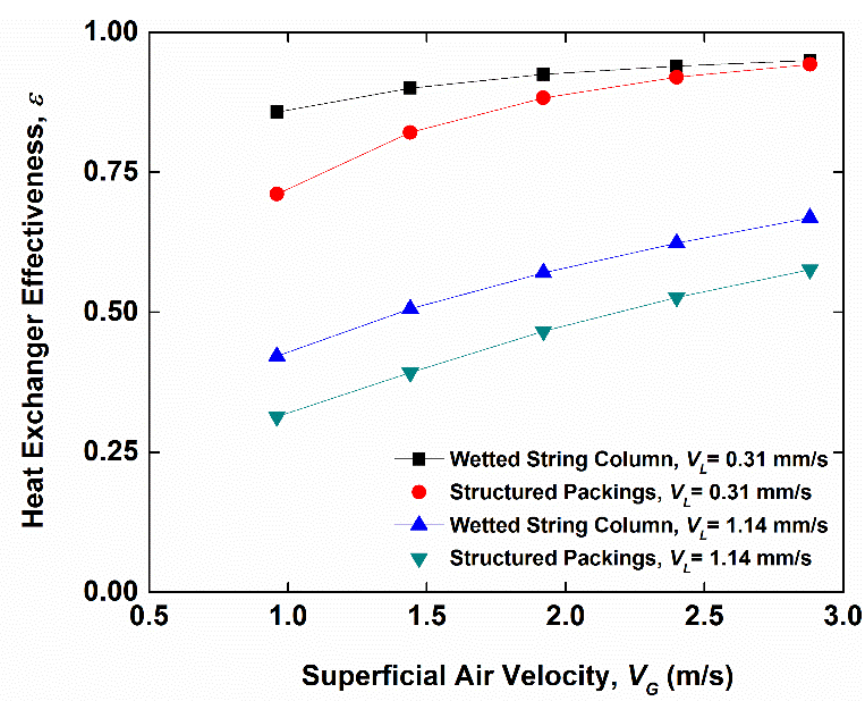

Fig. 20: The comparison of the heat exchanger effectiveness between the array of wetted strings and the vertical plate structured packing under the same gas and liquid supply conditions.

In contrast to the heat transfer performance, the air pressure drops of the two systems show significant difference (Fig. 21). At a given superficial liquid velocity, the air pressure drop along the structured packing is almost one order of magnitude higher than that along the wetted string column. This is consistent with the observations of prior studies [23], [24]. We also note that the air pressure drop along the array of wetted string is less sensitive to the superficial liquid velocity than the structured packing. This is in part because the fraction of the cross-sectional area available for air flows varies less for the array of wetted strings than the structured packing.

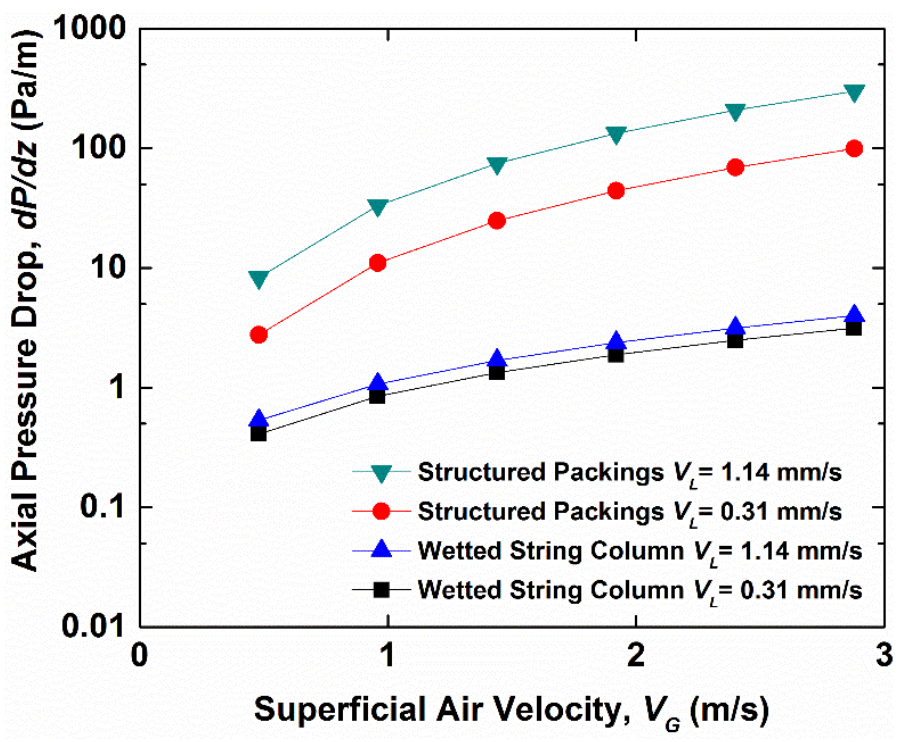

Fig. 21: The comparison in axial gas phase pressure drop between a wetted string column and a vertical plate structured packing at the same gas-liquid supply conditions

We repeat similar comparison for different values of the pitch $p$ and plate thickness $t$ under the fixed liquid and air superficial velocities. The results, shown in Fig. 22 and 23, are consistent with the earlier results in that the two types of heat exchange systems (the array of wetted strings and the vertical plate structured packing) show comparable heat transfer performance but very different air pressure drops. Both $\varepsilon$ and $d P / d z$ decrease as the pitch increases in part because the flow area is larger and the effective air velocity is lower. At a given pitch, the systems with thicker plates show slightly higher heat exchanger effectiveness and larger air pressure drop due in part to higher effective air velocities.

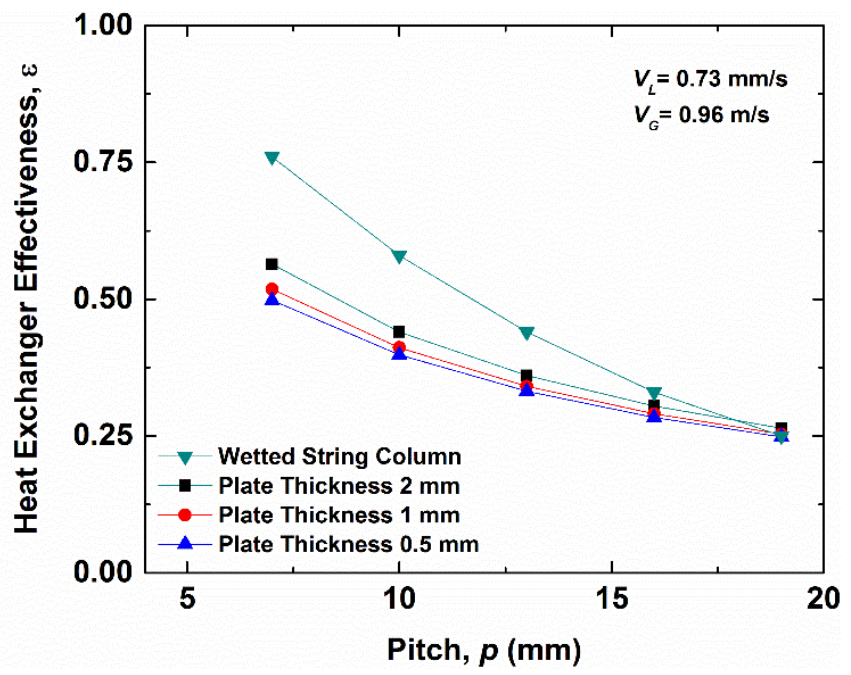

Fig. 22: The comparison in the heat exchanger effectiveness between the array of wetted strings and the vertical plate structured packing for different pitches and plate thickness.

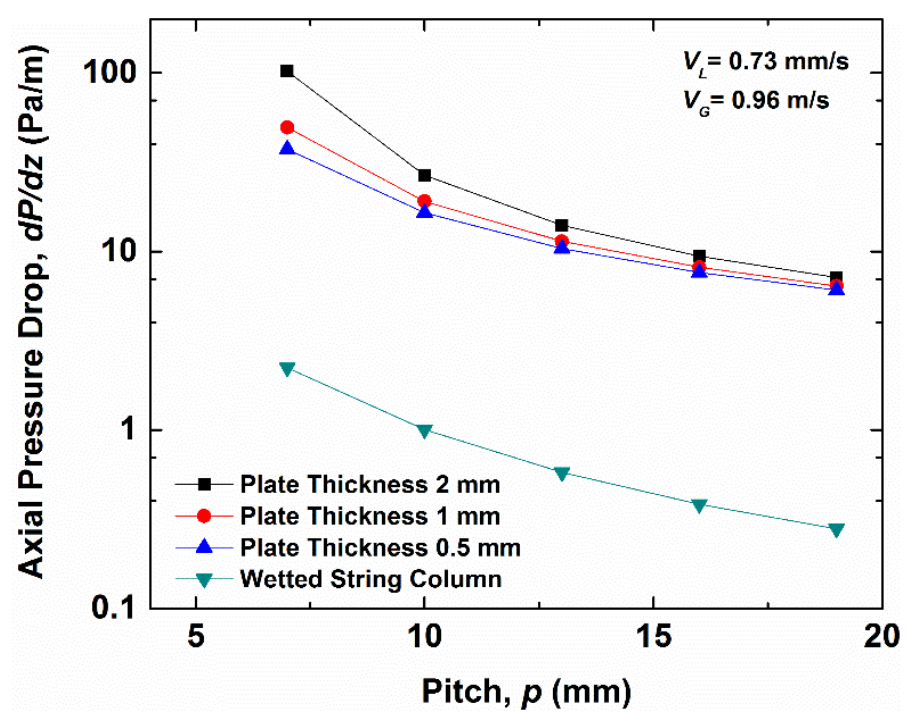

Fig. 23: The comparison in the pressure drop between the array of wetted strings and the vertical plate structured packing for different pitches and plate thickness.

\section{CONCLUSION}


In summary, we experimentally studied the relationship between flow characteristics and overall heat exchanger effectiveness for the thin liquid film flowing along a single string against a counterflowing air stream.

The experimental results demonstrate that the flow characteristics are affected by the liquid mass flow rate, air velocity, and nozzle radius. The increase in air velocity or nozzle radius for a fixed liquid flow rate leads to the increase in liquid beads volume but at a compromise of temporal frequency. Smaller liquid flow rate for a fixed nozzle only lowers the temporal bead frequency. Liquid substrate radius remains nearly unchanged for all cases.

The overall heat exchanger effectiveness is determined experimentally and validated by a numerical simulation. we show that the liquid mass flow rate and the air velocity are two dominant factors affecting heat transfer effectiveness whereas the details of the flow pattern only affect local bead-to-air heat transfer coefficients. The increase in air velocity or inter-bead spacing results in the increase in local bead-to-air heat transfer coefficient.

We also compare the heat exchanger effectiveness and the gas phase pressure drop between a wetted string column and a structured packing of vertical plates. The wetted string column shows comparable heat exchanger effectiveness but lower gas phase pressure drop than the structured packing.

The present work helps improve our understanding of the string-based direct-contact heat exchangers performance and helps establish a foundation for their systematical design and optimization.

\section{ACKNOWLEDGMENTS}

The present article is based on work supported in part by the National Science Foundation through grant CBET-1358034.

\section{REFERENCES}

[1] H. Zhai and E. S. Rubin, "Performance and cost of wet and dry cooling systems for pulverized coal power plants with and without carbon capture and storage," Energy Policy, vol. 38, no. 10, pp. 5653-5660, Oct. 2010.

[2] G. Yu, D. Zhao, L. Wen, S. Yang, and X. Chen, "Viscosity of ionic liquids: Database, observation, and quantitative structure-property relationship analysis," AIChE J., vol. 58, no. 9, pp. 2885-2899, 2012.

[3] K. Onda, H. Takeuchi, and Y. Okumoto, "Mass Transfer Coefficients Between Gas and Liquid Phases in Packed Columns," J. Chem. Eng. Jpn., vol. 1, no. 1, pp. 56-62, 1968.

[4] K. Onda, H. Takeuchi, and Y. Koyama, Effect of packing materials on the wetted surface area. 1990.

[5] A. F. Mills, Mass Transfer, 1 edition. Upper Saddle River, N.J: Prentice Hall, 2001.

[6] A. Mersmann and A. Deixler, "Packungskolonnen," Chem. Ing. Tech., vol. 58, no. 1, pp. 19-31, Jan. 1986.

[7] K. Uchiyama, H. Migita, R. Ohmura, and Y. H. Mori, "Gas absorption into 'string-of-beads' liquid flow with chemical reaction: application to carbon dioxide separation," Int. J. Heat Mass Transf., vol. 46, no. 3, pp. 457-468, Jan. 2003.
[8] R. Letan and E. Kehat, "The mechanics of a spray column," AIChE J., vol. 13, no. 3, pp. 443-449, May 1967.

[9] T. Nozaki, N. Kaji, and Y. H. Mod, "Heat Transfer to a Liquid Flowing Down Vertical Wires Hanging in a Hot Gas Stream: an Experimental Study of a New Means of Thermal Energy Recovery," HEAT Transf., vol. 6, pp. 63-68, 1998.

[10] H. Takahama and S. Kato, "Longitudinal flow characteristics of vertically falling liquid films without concurrent gas flow," Int. J. Multiph. Flow, vol. 6, no. 3, pp. 203-215, Jun. 1980.

[11] G. Grabbert and G. Wünsch, "Zur Hydraulik stark gekrümmter Rieselfilme," Freib. Forschungshefte A, vol. 517, pp. 61-83, 1973.

[12] J. W. Strutt and Lord Rayleigh, "On the instability of jets," Proc Lond. Math Soc, vol. 10, no. 4, 1878.

[13] D. Ter Haar, Collected papers of PL Kapitza, vol. 2. Elsevier, 2013.

[14] I. L. Kliakhandler, S. H. Davis, and S. G. Bankoff, "Viscous beads on vertical fibre," J. Fluid Mech., vol. 429, pp. 381-390, 2001.

[15] C. Ruyer-Quil, P. Treveleyan, F. Giorgiutti-Dauphiné, C. Duprat, and S. Kalliadasis, "Modelling film flows down a fibre," J. Fluid Mech., vol. 603, pp. 431-462, 2008.

[16] C. Ruyer-Quil and S. Kalliadasis, "Wavy regimes of film flow down a fiber," Phys. Rev. E, vol. 85, no. 4, p. 46302, Apr. 2012.

[17] C. Duprat, C. Ruyer-Quil, and F. Giorgiutti-Dauphiné, "Spatial evolution of a film flowing down a fiber," Phys. Fluids 1994-Present, vol. 21, no. 4, p. 42109, Apr. 2009.

[18] C. Duprat, C. Ruyer-Quil, S. Kalliadasis, and F. Giorgiutti-Dauphiné, "Absolute and Convective Instabilities of a Viscous Film Flowing Down a Vertical Fiber," Phys. Rev. Lett., vol. 98, no. 24, p. 244502, Jun. 2007.

[19] S. Muzaferija and M. Peric, "Computation of free-surface flows using interface tracking and interface-capturing methods," Adv. Fluid Mech., vol. 24, pp. 59-100, 1999.

[20] G. D. Wehinger, J. Peeters, S. Muzaferija, T. Eppinger, and M. Kraume, "Numerical simulation of vertical liquid-film wave dynamics," Chem. Eng. Sci., vol. 104, pp. 934-944, Dec. 2013.

[21] K. Hattori, M. Ishikawa, and Y. H. Mori, "Strings of liquid beads for gas-liquid contact operations," AIChE J., vol. 40, no. 12, pp. 1983-1992, 1994.

[22] H. Chinju, K. Uchiyama, and Y. H. Mori, "“String-ofbeads' flow of liquids on vertical wires for gas absorption," AIChE J., vol. 46, no. 5, pp. 937-945, May 2000.

[23] H. Migita, K. Soga, and Y. H. Mori, "Gas absorption in a wetted-wire column," AIChE J., vol. 51, no. 8, pp. 2190 2198, Aug. 2005.

[24] S. G. Pakdehi and S. Taheri, "Separation of Hydrazine from Air by Wetted Wire Column," Chem. Eng. Technol., vol. 33, no. 10, pp. 1687-1694, Oct. 2010.

[25] S. M. Hosseini, R. Alizadeh, E. Fatehifar, and A. Alizadehdakhel, "Simulation of gas absorption into string-of-beads liquid flow with chemical reaction," Heat Mass Transf., vol. 50, no. 10, pp. 1393-1403, Apr. 2014.

[26] S. A. Galledari, R. Alizadeh, E. Fatehifar, and E. Soroush, "Simulation of carbon dioxide absorption by 
monoethanolamine solution in wetted-wire column," Chem. Eng. Process. Process Intensif., vol. 102, pp. 5969, 2016.

[27] J. Grünig, T. Skale, and M. Kraume, "Liquid flow on a vertical wire in a countercurrent gas flow," Chem. Eng. $J$., vol. 164, no. 1, pp. 121-131, 2010.

[28] J. Grünig, E. Lyagin, S. Horn, T. Skale, and M. Kraume, "Mass transfer characteristics of liquid films flowing down a vertical wire in a counter current gas flow," Chem. Eng. Sci., vol. 69, no. 1, pp. 329-339, Feb. 2012.

[29] R. A. Seban and A. Faghri, "Evaporation and heating with turbulent falling liquid films," J. Heat Transf., vol. 98, no. 2, pp. 315-318, 1976.

[30] J. A. Shmerler and I. Mudawwar, "Local evaporative heat transfer coefficient in turbulent free-falling liquid films," Int. J. Heat Mass Transf., vol. 31, no. 4, pp. 731-742, 1988.

[31] J. A. Shmerler and I. Mudawwar, "Local heat transfer coefficient in wavy free-falling turbulent liquid films undergoing uniform sensible heating," Int. J. Heat Mass Transf., vol. 31, no. 1, pp. 67-77, 1988.

[32] S.-M. Yih and J.-L. Liu, "Prediction of heat transfer in turbulent falling liquid films with or without interfacial shear," AIChE J., vol. 29, no. 6, pp. 903-909, 1983.

[33] K. R. Chun and R. A. Seban, "Heat transfer to evaporating liquid films," J. Heat Transf., vol. 93, no. 4, pp. 391-396, 1971

[34] T. Fujita and T. Ueda, "Heat transfer to falling liquid films and film breakdown-I: Subcooled liquid films," Int. J. Heat Mass Transf., vol. 21, no. 2, pp. 97-108, 1978.

[35] G. J. Gimbutis and A. D. S. Sinkunas, "HEAT TRANSFER OP A TURBULENT WATER FILM AT DIFFERENT INITIAL FLOW CONDITIONS AND HIGH TEMPERATURE GRADIENTS," 1978.

[36] W. Wilke, "Warmeubertragung an rieselfilme," VDIForschungsheft, vol. 490, p. B28, 1962.

[37] B. G. Ganchev, V. M. Koglov, and V. V. Lozovetskiy, "A study of heat transfer to a falling fluid film at a vertical surface," Heat Transfer-Sov Res, vol. 4, pp. 102-110, 1972.

[38] Z. Zeng, G. Warrier, and Y. S. Ju, "Study of the Fluid Dynamics of Thin Liquid Films Flowing Down a Vertical
String With Counterflow of Gas," p. V08BT10A054, Nov. 2015.

[39] Z. Zeng, G. Warrier, and Y. S. Ju, "Flow and Heat Transfer in Liquid Films Flowing Over Highly Curved Surfaces," p. V002T06A012, Jul. 2015.

[40] Z. Zeng, G. Warrier, and Y. S. Ju, "Flow and Heat Transfer in Liquid Films Flowing Over Highly Curved Surfaces," in ASME 2015 International Technical Conference and Exhibition on Packaging and Integration of Electronic and Photonic Microsystems collocated with the ASME 2015 13th International Conference on Nanochannels, Microchannels, and Minichannels, 2015, p. V002T06A012-V002T06A012.

[41] C. Duprat, C. Ruyer-Quil, and F. Giorgiutti-Dauphiné, "Experimental study of the instability of a film flowing down a vertical fiber," Eur. Phys. J. Spec. Top., vol. 166, no. 1, pp. 63-66, Jan. 2009.

[42] W. M. Kays and A. L. London, "Compact heat exchangers," Jan. 1984.

[43] F. P. Incropera and A. S. Lavine, Fundamentals of Heat and Mass Transfer. John Wiley \& Sons, 2011.

[44] R. S. Ramachandran, C. Kleinstreuer, and T.-Y. Wang, "Forced Convection Heat Transfer of Interacting Spheres," Numer. Heat Transf. Part Appl., vol. 15, no. 4, pp. 471-487, Jun. 1989.

[45] B. Lloyd and R. Boehm, "Flow and heat transfer around a linear array of spheres," Numer. Heat Transf. Part Appl., vol. 26, no. 2, pp. 237-252, 1994.

[46] A. Mills, Heat and Mass Transfer. CRC Press, 1995.

[47] J. R. Fair, A. F. Seibert, M. Behrens, P. P. Saraber, and Z. Olujic, "Structured packing performance experimental evaluation of two predictive models," Ind. Eng. Chem. Res., vol. 39, no. 6, pp. 1788-1796, 2000.

[48] W. Brötz, "Über die Vorausberechnung der Absorptionsgeschwindigkeit von Gasen in strömenden Flüssigkeitsschichten1," Chem. Ing. Tech., vol. 26, no. 89, pp. 470-478, 1954.

[49] R. Kafesjian, C. A. Plank, and E. R. Gerhard, "Liquid flow and gas phase mass transfer in wetted-wall towers," AIChE J., vol. 7, no. 3, pp. 463-466, 1961.

[50] D. Bharathan, "Air-Water Countercurrent Annular Flow," Dartmouth Coll., Hanover, NH (USA). Thayer School of Engineering, EPRI-NP-1165, Sep. 1979. 